\title{
Emerging Multidrug Resistant Metallo- $\beta$-Lactamases (MBLs) Positive Klebsiella Species from Cloacal Swabs of Poultry Birds
}

\author{
Ejikeugwu Chika ${ }^{1^{*}}$, Iroha Ifeanyichukwu ${ }^{1}$, Oguejiofor Benigna ${ }^{1}$, Orji Okoro Loveday ${ }^{2}$, Eluu Stanley ${ }^{3}$, Okafor Collins ${ }^{4}$, Ovia Kenneth ${ }^{4}$ and Ezeador Chika $^{5}$ \\ ${ }^{1}$ Department of Applied Microbiology, Faculty of Sciences, Ebonyi State University, Abakaliki, P.M.B 053, Ebonyi State, Nigeria \\ ${ }^{2}$ Department of Pharmaceutics and Pharmaceutical Microbiology, Ahmadu Bello University, Zaria, Kaduna state, Nigeria \\ ${ }^{3}$ Department of Biological Sciences (Biotechnology Programme), Faculty of Sciences, Ebonyi State University, Abakaliki, P.M.B 053, Ebonyi State, Nigeria \\ ${ }^{4}$ Department of Biological Sciences, Evangel University, Akaeze, Ebonyi State, Nigeria
}

${ }^{5}$ Department of Microbiology and Parasitology, Faculty of Medicine, College of Health Sciences, P.M.B 5001, Nnamdi Azikiwe University Teaching Hospital, Nnewi, Nigeria

*Corresponding author: Ejikeugwu Chika, Department of Applied Microbiology, Faculty of Sciences, Ebonyi State University, Abakaliki, P.M.B 053, Ebonyi State, Nigeria, Tel: +2348097684562; E-mail: ejikeugwu_chika@yahoo.com

Received date: March 06, 2017; Accepted date: March 16, 2017; Published date: March 22, 2017

Copyright: (c) 2017 Ejikeugwu C, et al. This is an open-access article distributed under the terms of the Creative Commons Attribution License, which permits unrestricted use, distribution, and reproduction in any medium, provided the original author and source are credited.

\begin{abstract}
The increasing prevalence of antibiotic resistant bacteria in the community is a public health issue because this phenomenon compromises our ability to effectively treat infectious diseases since these organisms such as those that express metallo- $\beta$-lactamase $(\mathrm{MBL})$ are usually resistant to a wide variety of antibiotics. This study investigated the frequency of Klebsiella species from a local poultry farm that produced metallo- $\beta$-lactamase using phenotypic detection technique. Forty (40) samples from the cloacae of poultry birds were used for this study. Each sample was bacteriologically analyzed on MacConkey agar, and the isolated organism was identified by standard microbiology techniques. Susceptibility testing was done using disk diffusion technique, and the production of MBL was confirmed using disk diffusion technique in which EDTA was used as a chelating agent. Totally, 24 Klebsiella species isolates were isolated from the samples. High resistance of the Klebsiella species isolates was observed to oxacillin (100 \%), ofloxacin $(95.8 \%)$, gentamicin $(87.5 \%)$, ertapenem $(62.5 \%)$, cefoxitin $(58.3 \%)$ and ciprofloxacin $(87.5 \%)$. The expression of MBL was only confirmed phenotypically in $5(41.7 \%)$ Klebsiella species isolates. The indiscriminate use of antibiotics especially in the rearing of animals allows microbes to develop resistance through selective pressure. However, the timely and accurate detection of drug resistant microbes is critical to forestalling the emergence and spread these organisms in the community.
\end{abstract}

\begin{abstract}
Keywords: MBLs; Klebsiella species; Carbapenems; Carbapenemases; Nigeria

since these organisms defy the antimicrobial onslaught of some antibiotics. Thus, this study evaluated the occurrence of MBLproducing Klebsiella species using phenotypic detection technique.
\end{abstract}

\section{Introduction}

Metallo- $\beta$-lactamases (MBLs) are a type of carbapenemases that hydrolyze the carbapenems including imipenem, ertapenem and meropenem. MBLs are $\beta$-lactamases that belong to Ambler's class B type of enzymes, and they degrade a wide variety of $\beta$ - lactams, penicillins and the carbapenems [1]. Pathogenic bacteria that produce MBLs are usually susceptible to aztreonam, a monobactam; and they are inhibited by chelating agents. Organisms that express MBLs and other multidrug resistance enzymes are indeed a great threat and of clinical importance since these organisms are usually resistant to virtually all $\beta$-lactam drugs and some non $\beta$-lactam drugs like aminoglycosides, fluoroquinolones, and co-trimoxazoles used in clinical medicine today [1-4]. The presence of MBL genes in clinically important organisms threatens the efficacy of some available betalactam and non-beta-lactam agents [1,5]. Organisms producing MBLs in the community are of immense public health importance since they are usually resistant to a wide variety of antibiotics, and this makes these drugs to be less effective when used for therapy [6]. Such organisms harbouring genes for the production of MBLs and other multidrug resistant enzymes may cause serious infections. The emergence of multidrug resistant bacteria in both the hospital and non-hospital environments poses a serious public health challenge

\section{Materials and Methods}

\section{Sample collection}

Forty (40) samples from the cloacal region of poultry birds in a local poultry farm in Abakaliki metropolis were collected for this study. The samples were aseptically collected by inserting a sterile swab sticks in the cloacal region of the poultry birds at a depth of $3 \mathrm{~cm}$ and rotated at angle $360^{\circ}$. The swab sticks was returned to their respective containers, labeled and transported to the Microbiology Laboratory Unit of Ebonyi State University, Abakaliki for further bacteriological analysis.

\section{Culture and identification of Klebsiella species}

Each of the swab sticks were dipped in test tubes containing $5 \mathrm{ml}$ of freshly prepared nutrient broth (Oxoid, UK) and the tubes were loosely covered with cotton wool, and incubated at $30^{\circ} \mathrm{C}$ for about $18-24$ hours. Bacterial growth was indicated by the presence of turbidity in the tubes. Tubes showing turbidity (as indication of bacterial growth) were aseptically subcultured onto freshly prepared MacConkey agar (Oxoid, UK) plates and incubated at $30^{\circ} \mathrm{C}$ for $18-24$ hours. Suspect colonies of Klebsiella species was subcultured onto freshly prepared 
MacConkey agar plates for the isolation of Klebsiella species which form mucoid colonies on MacConkey agar. The identification of Klebsiella species was done using standard microbiology techniques [7].

\section{Antibiotic susceptibility testing}

Susceptibility testing was done on Mueller-Hinton (MH) agar (Oxoid, UK) plates by disk diffusion method as per the Clinical Laboratory Standard Institute guideline using imipenem $(10 \mu \mathrm{g})$, meropenem $(10 \mu \mathrm{g})$, ertapenem $(10 \mu \mathrm{g})$, amikacin $(10 \mu \mathrm{g})$, ofloxacin $(5$ $\mu \mathrm{g})$, ceftazidime $(30 \mu \mathrm{g})$, ceftriaxone $(30 \mu \mathrm{g})$, cefotaxime $(30 \mu \mathrm{g})$, ciprofloxacin $(10 \mu \mathrm{g})$, oxacillin $(1 \mu \mathrm{g})$, cefoxitin $(30 \mu \mathrm{g})$ and gentamicin $(10 \mu \mathrm{g})$. Briefly, the $\mathrm{MH}$ agar plates were swabbed with the test isolates (adjusted to 0.5 MacFarland turbidity standards); and each of the antibiotic disk was aseptically placed on the $\mathrm{MH}$ agar plates at a distance of $15 \mathrm{~mm}$. The susceptibility test plates were incubated at $30^{\circ} \mathrm{C}$ for 18-24 hours and the zones of inhibition diameter was measured, recorded and interpreted according to the CLSI criteria $[6,8]$.

\section{MBL screening test}

To screen bacterial isolates for the production of MBLs, it has been recommended to use any of the carbapenems including meropenem and imipenem since MBL positive bacteria are resistant to the carbapenems $[6,8]$. The Kirby-Bauer disk diffusion technique was used, and each of the carbapenems including meropenem, ertapenem and imipenem was placed at a distance of $20 \mathrm{~mm}$ apart on $\mathrm{MH}$ agar plates already inoculated with the test bacterial isolates and the plates were incubated at $30^{\circ} \mathrm{C}$ for $18-24$ hours. MBL production was suspected when the test organism showed reduced susceptibility to any of the carbapenems. As per the CLSI criteria, isolates showing inhibition zone diameter (IZD) of $\leq 23 \mathrm{~mm}$ were suspected to produce $\mathrm{MBL}$ and these isolates were subjected to phenotypic confirmation test.

\section{Inhibition based assay for confirmation of MBL production}

Test organisms found to be resistant to imipinem or meropenem (as indicated in the screening test) was evaluated phenotypically for the production of MBLs as was previously described [4,6]. Standard antibiotic disks of imipenem $(10 \mu \mathrm{g})$ and meropenem $(10 \mu \mathrm{g})$, impregnated with EDTA were aseptically placed on $\mathrm{MH}$ agar plates already swabbed with the test bacterial isolates (adjusted to 0.5 MacFarland turbidity standards), and supplementary imipenem (10 $\mu \mathrm{g})$ and meropenem $(10 \mu \mathrm{g})$ disks without EDTA were also placed alongside antibiotic disks impregnated with EDTA. All the plates were incubated at $30^{\circ} \mathrm{C}$ for $18-24$ hours and zones of inhibition were measured, recorded and interpreted as per the CLSI criteria. A difference of $\geq 7 \mathrm{~mm}$ between the zones of inhibition of any of the carbapenem disks with and without the chelating agents infers metallo- $\beta$-lactamase production phenotypically $[6,9]$.

\section{Results}

This study phenotypically evaluated the occurrence of Klebsiella species producing metallo- $\beta$-lactamase from the cloacal swabs of poultry birds in a local poultry farm in Abakaliki metropolis of Ebonyi State, Nigeria. The frequency of isolation of Klebsiella species from the cloacal swab samples of the poultry birds is shown in Table 1. A total of 24 isolates of Klebsiella species were isolated from the cloacal swab samples of the poultry birds over a period of one month (July, 2016), and these isolates were positive for urease test and citrate test (Table 1).
Table 2 shows the result of antimicrobial susceptibility profile of the isolated Klebsiella species to some commonly available antibiotics. The antimicrobial susceptibility pattern revealed that the Klebsiella species isolates were more susceptible to amikacin (87.5\%), imipenem (95.8\%), meropenem (91.7\%), ceftriaxone $(66.7 \%)$, cefotaxime $(62.5 \%)$ and ceftazidime (58.3\%). However, the isolates showed high resistance to ertapenem, ofloxacin, ciprofloxacin, oxacillin, gentamicin and cefoxitin (Table 2).

\begin{tabular}{|l|l|l|l|l|l|}
\hline & $\begin{array}{l}\text { No of } \\
\text { sampl } \\
\text { es }\end{array}$ & $\begin{array}{l}\text { Klebsiell } \\
a \\
\text { species }\end{array}$ & $\begin{array}{l}\text { Urease } \\
\text { test }\end{array}$ & $\begin{array}{l}\text { Citrate } \\
\text { test }\end{array}$ & $\begin{array}{l}\text { Gram } \\
\text { staining } \\
\text { reaction }\end{array}$ \\
\hline $\begin{array}{l}\text { Cloacal swabs of poultry } \\
\text { birds }\end{array}$ & 40 & $24(60)$ & + & + & $\begin{array}{l}\text { Gram } \\
\text { negative }\end{array}$ \\
\hline
\end{tabular}

Table 1: Frequency of Klebsiella species isolation

\begin{tabular}{|c|c|c|c|}
\hline $\begin{array}{l}\text { Antibiotics } \\
(\mu \mathrm{g})\end{array}$ & n (\%)Resistance & $\begin{array}{l}\mathrm{n} \\
\text { Intermediate }\end{array}$ & $\begin{array}{l}\mathrm{n} \\
\text { Susceptibility }\end{array}$ \\
\hline AK (10) & $1(4.2)$ & $2(8.3)$ & $21(87.5)$ \\
\hline CRO (30) & $8(33.3)$ & $0(0.0)$ & $16(66.7)$ \\
\hline CAZ (30) & $9(37.5)$ & $1(4.2)$ & $14(58.3)$ \\
\hline FOX (30) & $14(58.3)$ & $4(16.6)$ & $6(25.0)$ \\
\hline CTX (30) & $9(37.5)$ & $0(0.0)$ & $15(62.5)$ \\
\hline IPM (10) & $0(0.0)$ & $1(4.1)$ & $23(95.8)$ \\
\hline $\mathrm{CN}(10)$ & $21(87.5)$ & $0(0.0)$ & $3(12.5)$ \\
\hline OX (1) & $24(100)$ & $0(0.0)$ & $0(0.0)$ \\
\hline MEM (10) & $0(0.0)$ & $2(8.3)$ & $22(91.7)$ \\
\hline OFX (5) & $23(95.8)$ & $0(0.0)$ & $1(4.2)$ \\
\hline ETP (10) & $15(62.5)$ & $0(0.0)$ & $9(37.5)$ \\
\hline CIP (10) & $21(87.5)$ & $2(8.3)$ & $1(4.2)$ \\
\hline
\end{tabular}

Table 2: Antimicrobial susceptibility profile of 24 Klebsiella species isolated from the cloacal swabs of poultry birds. Key: $\mathrm{CN}=$ gentamicin, $\mathrm{OX}=$ oxacillin, $\mathrm{OFX}=$ ofloxacin, $\mathrm{ETP}=$ ertapenem, $\mathrm{CIP}=$ ciprofloxacin, $\mathrm{AK}=$ amikacin, $\mathrm{CRO}=$ ceftriaxone, $\mathrm{CAZ}=$ ceftazidime, $\mathrm{IPM}=$ imipenem, FOX=cefoxitin, $\mathrm{MEM}=$ meropenem, $\mathrm{CTX}=$ cefotaxime.

\begin{tabular}{|l|l|l|l|l|}
\hline $\begin{array}{l}\text { Organism } \\
(\mathbf{n = 2 4 )}\end{array}$ & Sample source & $\begin{array}{l}\text { Suspecte } \\
\mathbf{d} \text { MBL } \\
\text { producer } \\
\text { s n (\%) }\end{array}$ & $\begin{array}{l}\text { MBL } \\
\text { positive } \\
\mathbf{n}(\%)\end{array}$ & $\begin{array}{l}\text { MBL } \\
\text { negativ } \\
\mathbf{n}(\%)\end{array}$ \\
\hline $\begin{array}{l}\text { Klebsiella } \\
\text { species }\end{array}$ & $\begin{array}{l}\text { Cloacal swabs of poultry } \\
\text { birds }\end{array}$ & $12(50)$ & $5(41.7)$ & $7(58.3)$ \\
\hline
\end{tabular}

Table 3: Distribution of MBL positive Klebsiella species and MBL negative Klebsiella species from cloacal swabs of poultry birds.

Table 3 shows the occurrence of MBL positive Klebsiella species in this study. Out of the 24 isolates of Klebsiella species screened for the production of MBLs, 12 Klebsiella species isolates were suspected to express MBLs phenotypically. However, only 5 (41.7\%) isolates of 
Citation: Chika E, Ifeanyichukwu I, Benigna O, Loveday OO, Stanley E, et al. (2017) Emerging Multidrug Resistant Metallo- $\beta$-Lactamases (MBLs) Positive Klebsiella Species from Cloacal Swabs of Poultry Birds. J Bacteriol Parasitol 8: 305. doi:10.4172/2155-9597.1000305

Page 3 of 3

Klebsiella species were phenotypically confirmed to produce MBLs by the inhibition-based assay technique used in this study (Table 3).

\section{Discussion}

The expression of carbapenemases including metallo- $\beta$-lactamases (MBLs) is one of the major mechanisms of carbapenem resistance in Gram negative bacteria; and the production of this enzyme gives the organism the ability to ward-off the antimicrobial action of the carbapenems - which are considered potent agents for the treatment of infections caused by bacteria that produce extended spectrum $\beta$ lactamases (ESBLs). In this study, the antimicrobial susceptibility profile and production of MBLs by Klebsiella species from the cloacal swabs of poultry birds was investigated phenotypically. Out of the 40 cloacal swab samples that were bacteriologically analyzed in this study, a total of 24 Klebsiella species was isolated. All the isolated Klebsiella species showed high resistance to the tested antibiotics. The Klebsiella species isolates was resistant to ciprofloxacin (87\%), ofloxacin $(95.8$ $\%)$, oxacillin (100\%), gentamicin (87.5\%), cefoxitin (58.3\%), ceftazidime $(37.5 \%)$ and ceftriaxone $(33.3 \%)$. The Klebsiella species were also resistant to ertapenem but susceptible to imipenem and meropenem. The high resistance profile of the isolated Klebsiella species in this study is in agreement to a similar and recent work carried out in Japan by Okazaki et al. [10] in which $K$. pneumoniae isolated from a non-hospital environment was reported to be resistant to some non-beta-lactam and beta-lactam antibiotics including gentamicin, amikacin and cefotaxime. Totally, 12 isolates of Klebsiella species were suspected to express MBL when tested. However, only 5 (41.7\%) Klebsiella species isolates was phenotypically confirmed to express MBL by the inhibition-based assay. The frequency of MBL positive Klebsiella species as reported in this study is similar to a previously conducted work by Ejikeugwu et al. [6] in which MBL expression was phenotypically confirmed in Klebsiella species. In Nepal, Bora et al. [11] also reported that Klebsiella pneumoniae from clinical isolates expressed MBLs. In another related study, Enwuru et al. [12] in Lagos, Nigeria also reported that Klebsiella species from hospital environments expressed MBL phenotypically, and that these organisms are resistant to some commonly available antibiotics. The emergence and spread of MBL-producing Klebsiella species in the community as reported in this study may portend public health issues if these organisms are transmitted to humans via the food chain. Conclusively, this study reports the occurrence and expression of metallo- $\beta$-lactamase (MBL) in Klebsiella species from a non-hospital source, particularly from poultry birds; and the isolates were found to be resistant to some commonly used antibiotics. We therefore recommend the timely and accurate detection of organisms producing MBLs since such measures will help to prevent the dissemination of MBL positive bacteria in either the community or hospital environment.

\section{References}

1. Walsh TR, Toleman MA, Poirel L, Nordmann P (2005) Metallo-betalactamases: the quiet before the storm? Clin Microbiol Rev 18: 306-325.

2. Pitout JDD, Chow BL, Gregson DB, Laupland KB, Elsayed S, et al. (2007) Molecular epidemiology of Metallo - $\beta$ - Lactamase - producing Pseudomonas aeruginosa in the Calgary Health Region: Emergence of VIM-2 producing isolates. J Clin Microbiol 45: 294-298.

3. Varaiya A, Kulkarni N, Kulkarni M, Bhalekar P, Dogra J (2008) Incidence of metallo beta - lactamase producing Pseudomonas aeruginosa in ICU patients. Indian J Med Res 127: 398-402.

4. Chika E, Chijioke E, Ifeanyichukwu I, Jerry O, Stanley E, et al. (2016) Antibiogram and Detection of Metallo-Beta-Lactamase (MBL) positive Escherichia coli isolates from abattoir. Nat Sci 14: 65-69.

5. Franco MR, Caiaffa-Filho HH, Burattini MN, Rossi F (2010) Metallo beta - lactamases among imipenem resistant Pseudomonas aeruginosa in a Brazillian University hospital. Clinics 65: 825-829.

6. Chika E, Ifeanyichukwu I, Carissa D, Thomas A, Okoro O (2016) Occurrence of Metallo-Beta-Lactamase-Producing Enterobacteriaceae in Abakaliki, Nigeria. Int J Appl Pharm Sci Res 1: 70-75.

7. Cheesbrough M (2006) District Laboratory Practice in Tropical Countries. 2nd edn, Cambridge University Press, UK. P: 178-187.

8. Clinical Laboratory Standard Institute, CLSI (2011) Performance standards for antimicrobial disk susceptibility test. Fifteenth informational supplement, CLSI document M100-S15. Wayne, PA. USA.

9. Aibinu I, Nwanneka T, Odugbemi T (2007) Occurrence of ESBLs and MBL in Clinical Isolates of Pseudomonas aeruginosa from Lagos, Nigeria.

10. Okazaki R, Hagiwara S, Kimura T, Tokue Y, Kambe M, et al. (2016) Metallo-ß-lactamase-producing Klebsiella pneumoniae infection in a non-hospital environment. Acute Med Surg 3: 32-35.

11. Bora A, Sanjana R, Jha BK, Mahaseth SN, Pokharel K (2014) Incidence of metallo-beta-lactamase producing clinical isolates of Escherichia coli and Klebsiella pneumonia in central Nepal. BMC Res Notes 7: 557.

12. Enwuru NV, Enwuru CA, Ogbonnia SO, Adepoju-Bello AA (2011) Metallo-ß-lactamase production by Escherichia coli and Klebsiella species isolated from hospital and community subjects in Lagos, Nigeria. Nat Sci 9: 1-5. 